\title{
Effect of imparting antimicrobial coating on organic cotton fabric using yashtimadhu for medical application
}

\begin{abstract}
Medical textiles are one of the most rapidly expanding sectors in the technical textile market. In the recent years, Comfort has become mandatory in medical textiles. Textiles with antimicrobial functional Finishes are given to provide comfort to the human beings. The development of antimicrobial coated fabric and effect of finish are achieved by using the herb-Yashtimadhu. The extraction of the herb is done by direct extraction method by using ethanol as the selected solvent among the other solvents like methanol, ethanol, chloroform, acetone and distilled water based on different polarity ranges and it is applied on to the cotton fabric by pad-dry-cure method in an optimized process conditions. The optimized conditions are Temperature- $35^{\circ} \mathrm{C}$, Time-3hrs, pH-6 and Concentration-20\%. The coated and uncoated samples are tested in standard antimicrobial tests namely AATCC 100, AATCC 147, AATCC 30 Agar Diffusion and Broth Dilution tests.
\end{abstract}

Volume 3 Issue 3 - 2017

\section{Krishnaveni $\vee$}

Department of Fashion Technology, Kumaraguru College of Technology, India

\section{Correspondence: Krishnaveni V, Associate Professor, Department of Fashion Technology, Kumaraguru College of Technology, Coimbatore, Tamilnadu, India, Tel 9486 | I 2284,} Email krishnassstyle@gmail.com

Received: April 01, 2017 | Published: November 13, 2017

Keywords: yashtimadhu, antimicrobial, box-behnken design micro organisms, medical textiles

\section{Introduction}

Medical Textiles are one of the fast growing sectors of the global Technical Textile industry and one of the dynamically expanding sectors. The inherent properties of textile fibers provide the opportunity for the growth of micro organisms. ${ }^{1}$ Microbes include a variety of micro organisms like bacteria, fungi, algae and viruses, stain the fabric and Detroit the performance properties of fabrics. Comfort is a pleasant state of physiological, psychological and physical harmony between a human being and the environment. ${ }^{2-4}$

But according to the old saying "Prevention is better than Cure", controlling of diseases before humans get affected is important. So controlling can be done through the second skin of human-Clothing. The controlling of micro organisms is tedious process; washing can only arrest the micro organisms and does not destroy them. Comfort is more fortuitous for the common healthy people. ${ }^{5}$ Therefore it is necessity of the manufacture to provide comfort in all medical. With this threat gaining its stature day by day, there are a wide variety of commercial anti-microbial agents but it gives toxic effect to the environment and the wearers. ${ }^{6-8}$ Eco Textiles gain utmost importance as one of the most useful resources that help promote new innovations, in an eco-friendly manner. The natural plants are commonly used for curing the diseases. One of the natural plants Liquorice (Yashtimadhu) is one of the most popular medicinal herbs in India and also in abroad. The roots of Glycyrrhiza glabra contain a substance called glycyrrhizin that posse's anti-inflammatory property and also it's used for healing the wounds. Basically with a view of protecting the wearer and the textile substrate, the anti-microbial finish, is a recent innovation in finishes used for health care applications.

The present study investigation aims at developing natural antimicrobial finished fabrics from the herb Glycyrrhiza glabra (Yashtimadhu) plant extracts for controlling micro organism growth in medical application. The antimicrobial effect of the coated samples is tested and the results are discussed in this article.

\section{Materials and methods}

\section{Selection of material}

Organic cotton fabric with the following specification was desized, scoured and bleached prior to the application of finish.

Yarn count: $50 \times 50$

Fabric count: $80 \times 80$

Weave: Twill

Gsm: 170

\section{Selection of antimicrobial plant}

Yashtimadhu (Glycyrrhiza glabra) is the plant species chosen for the study. The roots of Yashtimadhu were shadow dried and made into a fine powder (Figure 1). ${ }^{9}$

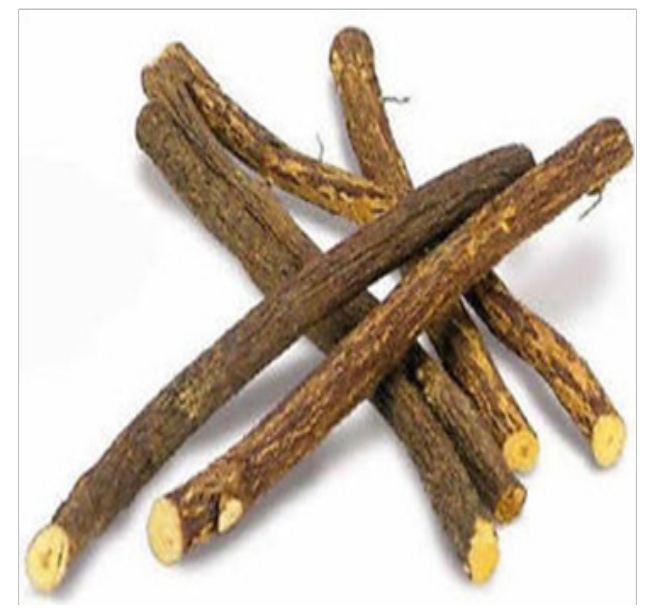

Figure I Glycyrrhiza Glabra Root. 


\section{Preparation of extract}

The active compounds in the herbal powder that has affinity to those polar particles present in the solvents get separated. Based on the type of Extraction method and Agar Diffusion method (AATCC 147) the suitable solvent selected was ethanol.

\section{Method of finish application}

The temperature, time, $\mathrm{pH}$ and the $\mathrm{M}$ : $\mathrm{L}$ ratio was optimized using the Box and Benhen method. The optimized conditions were namely Temperature- $35^{\circ} \mathrm{C}$, Time- $3 \mathrm{hrs}$, $\mathrm{pH}-6$ and Concentration- $20 \%$ The herbal extracts was applied on to cotton fabric at the material liquor ratio of $1: 10$ by pad-dry cure method using pneumatic padding mangle with standard conditions. The mordant alum was used as a binding agent to fix the herbal extract on to fabric.The treated fabric sample was then dried at $80^{\circ} \mathrm{C}$ for 10 minutes to remove the moisture. Finally the fabric samples were tested for antimicrobial activity as per the standard test methods.

\section{Assessment of antibacterial activity in yashtimadhu} extract coated fabric samples

AATCC-100-1998 (USA): Quantitative assessment of antibacterial finishes on textiles-measures the degree of antibacterial activity-broth dilution test: The 1" $\times 1$ " Samples were prepared from the Yashtimadhu (untreated, $20 \%, 40 \%$ and $60 \%$ treated). $500 \mathrm{ml}$ Elenmeyer conical flasks containing $50 \mathrm{ml}$ of nutrients broth were prepared and sterilized at $121^{\circ} \mathrm{C}$ for 15 minutes. It was then allowed to cool. The fabric samples were then transferred aseptically into the conical flasks respectively. These were incubated at $37^{\circ} \mathrm{C}$ for 24 hours in shaker at $121 \mathrm{rpm}$. After incubation their absorbance were measured at $600 \mathrm{~nm}$.

AATCC-147-1998 (USA): Qualitative antibacterial assessment of diffusible antibacterial agents ("quick method")-agar diffusion Test: The $55 \mathrm{ml}$ of nutrient agar was prepared and sterilized at $121^{\circ} \mathrm{C}$ for 15 minutes. Petri plates were autoclaved in hot air oven at $121^{\circ} \mathrm{C}$ for 30 minutes. $20 \mathrm{ml}$ of Nutrient agar was poured into each of these plates and were allowed to solidify. A series of 8 test tubes containing $4.5 \mathrm{ml}$ of sterile water was taken. $0.5 \mathrm{ml}$ of culture from nutrient broth containing the $100 \%$ treated samples was transferred aseptically into the first test tube. Serial dilution was carried out until its reduced dilution was $10^{\wedge}(-8) .100$ micro liters of $10(-8)$ diluted culture was taken aseptically and poured onto the petri plates. The plates were incubated at $37^{\circ} \mathrm{C}$ for $16-18$ hours. Similar procedure was carried out for untreated sample; sample treated with $40 \%$ and $60 \%$ concentrations.

\section{Assessment of antifungal activity in yashtimadhu ex- tract coated fabric samples}

AATCC 30-1993: Antifungal activity, assessment of textile material: mildew and rot resistance of textile material-broth dilution test: $400 \mathrm{ml}$ Elenmeyer conical flask containing $50 \mathrm{ml}$ of PD broth was prepared and sterilized at $121^{\circ} \mathrm{C}$ for 15 minutes. It was then allowed to cool. The fabric samples were transferred aseptically into the conical flasks respectively. These were kept at room temperature for 3 days. Then the growth of fungi in the conical flask was observed after 3 days.

\section{Finish wash durability test}

The durability of the treated fabric was conducted for the sample of size $4 \times 4 \mathrm{~cm}$. The sample chosen for the test was washed for $5-25$ cycles in standard temperature $37^{\circ} \mathrm{C}$ and with standard detergent.

\section{Results and discussion}

\section{AATCC-100-1998 (USA)}

Quantitative assessment of antibacterial finishes on textilesmeasures the degree of antibacterial activity-broth dilution test: The absorbance of the sample is directly proportional to the concentration of the cells in the sample. The absorbance values of the samples are compared. It is found that the fabric finished with $20 \%$ conc. gives low absorbance values when compared to the untreated fabric. This indicates that $20 \%$ conc. treated fabric does not support the growth of bacteria, the anti bacterial property (Table 1).

\section{AATCC-1 47 - 1998 (USA)}

Qualitative antibacterial assessment of diffusible antibacterial agents ("quick method")-agar diffusion Test: After incubation, the plates were observed for bacterial growth. Then the numbers of colonies were counted for each plate (Figure 2). The antibacterial activity of Glycyrrhiza Glabra extract coated fabrics was analyzed. The zone of inhibition is more when compared to the untreated fabric. This means that the fabric does not support the growth of bacteria because of the absorbency of the extract on the fabric. The extract was highly absorbed by the fabric and the wet pickup ratio was appreciable more than $90 \%$ of original extract (Table 2 ).

Table I AATCC - 100 Absorbance tests at $670 \mathrm{~nm}$

\begin{tabular}{ll}
\hline \multirow{2}{*}{ Sample } & Reduction values (at 670nm) \\
\cline { 2 - 2 } & Staphylococcus aureus \\
\hline Untreated fabric & 1.01 \\
$20 \%$ concentration Sample(I hour) & 0.95 \\
$20 \%$ concentration Sample(2 hour) & 0.74 \\
\hline
\end{tabular}

Table 2 Zone of inhibition for Glycyrrhiza Glabra with Agar Diffusion Method

\begin{tabular}{ll}
\hline \multirow{2}{*}{ Sample } & $\begin{array}{l}\text { Anti-bacterial activity } \\
\text { (Zone of inhibition in } \mathbf{~ m m})\end{array}$ \\
\cline { 2 - 2 } & Staphylococcus aureus \\
\hline Yashtimadhu extract finished fabric (20\%) & 19 \\
Yashtimadhu extract finished fabric (40\%) & 22 \\
Yashtimadhu extract finished fabric (60\%) & 24 \\
Untreated fabric & 0
\end{tabular}

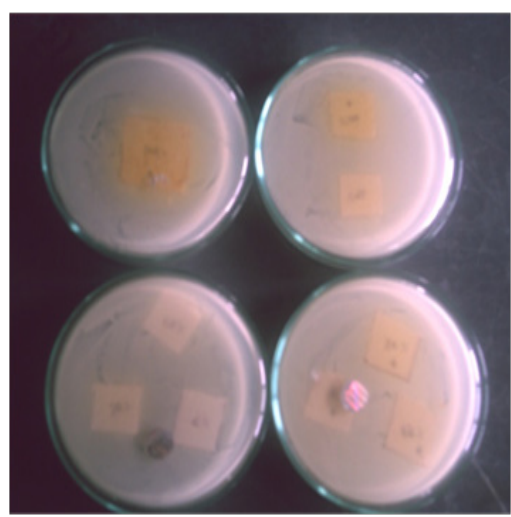

Figure 2 Zone of inhibition of yashtimadhu extract coated fabric samples. 


\section{AATCC-30-1993:Anti-fungal activity, assessment of textile material: mildew and rot resistance of textile material (broth dilution test)}

It was found that there was less growth of fungi in the conical flask containing $50 \%$ concentration sample when compared to the untreated sample from the picture (Figure 3). This indicates that the $50 \%$ treated fabric has better anti fungal property (Tables 3 ).

\section{Wash durability test}

From the obtained absorbance value, it can be concluded that the herbal finished product can withstand up to 15-18 washes (Table 4).

Table 3 AATCC-30 Absorbance Tests at 670 Nm

\begin{tabular}{ll}
\hline \multirow{2}{*}{ Sample } & Absorbance values (at 670nm) \\
\cline { 2 - 2 } & Aspergillus niger \\
\hline Untreated fabric & 1.02 \\
$20 \%$ concentration Sample & 0.84 \\
\hline
\end{tabular}

Table 4 Wash Durability Test

\begin{tabular}{lll}
\hline Wash durability & & $\begin{array}{l}\text { Absorbance value (at } \\
\mathbf{6 7 0} \mathbf{n m} \text { ) }\end{array}$ \\
\hline Untreated fabric & Before wash & 1.07 \\
& Before wash & 0.76 \\
& After 5 wash & 0.89 \\
Treated fabric & After 10 wash & 0.94 \\
& After 15 wash & 0.99 \\
& After 20 wash & 1.24 \\
& After 25 wash & 1.37 \\
\hline
\end{tabular}
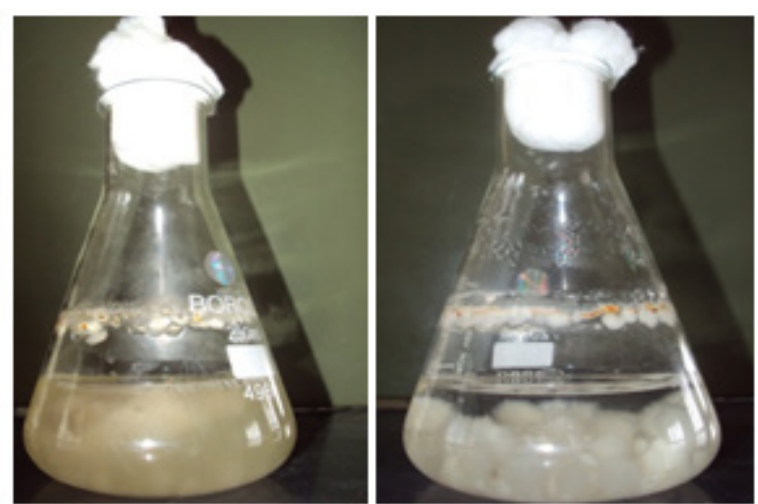

Figure 3 Zone of inhibition of yashtimadhu extract coated fabric samples.

\section{Conclusion}

Multi functional products are more and more often projected and realized where even contrasting performances must coexist and cohabit. The $20 \%$ conc. treated fabric was proved to possess best antimicrobial property. The study reveals that the Glycyrrhiza Glabra herb coated fabric is found to be very hygienic with less fungi and bacteria as well as making the cloth much softer than before. This finish is very much cost effective and eco-friendly. The wash durability test revealed that the finish was able to withstand 12-18 washes and wet pickup ratio also found to be good. Now-a-days fabrics with comfort properties are more important in medical and other apparel categories. Hence this herbal yashtimadhu finish will help to resist microbes and also provide coolant effect to the eyes. In a nutshell this study has open doors for production better eco-friendly medically treated cotton fabrics.

\section{Acknowledgements \\ None.}

\section{Conflict of interest}

Author declares there is no conflict of interest in publishing the article.

\section{References}

1. Brojeswari Das, Das A, Kothari VK, et al. Moisture transmission through textiles Part II: Evaluation Methods and Mathematical Modelling. AUTEX Research J. 2007;7(3):194-216.

2. Christner BC, Morris CE, Foreman CM, et al. Ubiquity of biological ice nucleators in snowfall. Science. 2008;319(5867):1214.

3. Charan RB. Development in environment friendly functional finishes for cotton fabrics and garment. India: NCM; 2003. p. 21.

4. Usha Sayed, Laxmikant SJ. Application of Herbs on Fabric. Colourage. 2006;53(4):129-133.

5. Amandeep Kaur, Chakraborty JN. Essence of Healthy and Motivative Clothing. Asian Textile J. 2009. p. 37-39.

6. Rybicki E. The classification of organisms at the edge of life, or problems with virus systematic. S Aft J Sci. 1990;86(4):182-186.

7. Slater K. Human comfort. USA: Springfield, Charles C Thomas Publisher; 1985. p. 249.

8. Mucha H, Hoter D, Swerev M. Antimicrobial Finishes and Modification. Melliand Internationl. 2002. p. 148-151.

9. Feng P, Weagant S, Grant M. Enumeration of Escherichia coli and the Coliform Bacteria. Bacteriological Analytical Manual. 2002. 